\title{
A reflection on the role, potential and challenges of transdisciplinarity at the University of Fort Hare
}

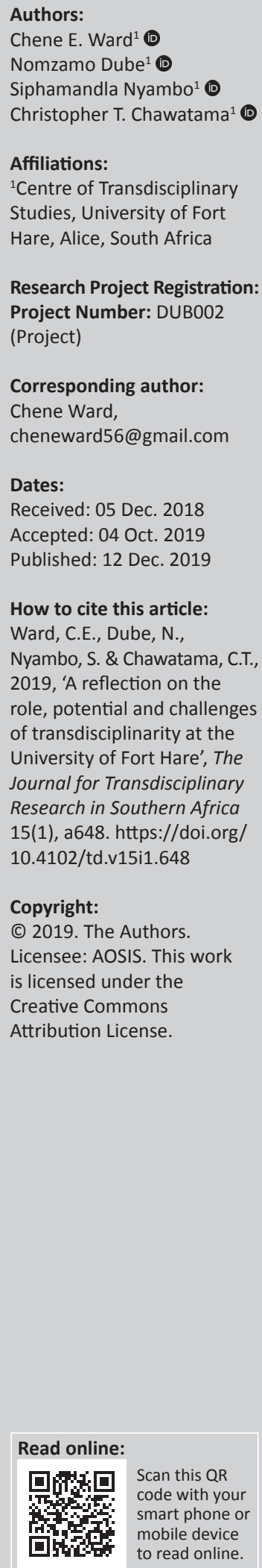

The world is currently grappling with a myriad of challenges such as unemployment, poverty, inequality, violent crimes and HIV and AIDS. These challenges exist on multiple levels and are viewed from different perspectives by scholars coming from diverse disciplines, hence they demand to be tackled using a transdisciplinary approach. As part of the University of Fort Hare's radical reconstruction of its intellectual project, the Centre for Transdisciplinary Studies (CTS) was established to facilitate and promote a wider intellectual engagement and research amongst academics and students across different disciplines. This research thus seeks to reconceptualise CTS' objectives through exploring the academics' understanding of transdisciplinarity, its role, transformative potential and challenges at the University of Fort Hare, South Africa. The research was conducted through qualitative semi-structured interviews with the university's academic staff members representing faculties of health, law, social sciences and humanities, management and commerce, science and agriculture, education and the Teaching and Learning Centre. Data were analysed by thematic data analysis. The findings of the study concluded that there was no consensus amongst academics on the definition of transdisciplinarity. Academics defined it as either the merging or collaboration of disciplines. Some used the term interchangeably with interdisciplinarity and multi-disciplinarity. The findings positioned the role of CTS as that of raising transdisciplinary awareness and coordinating transdisciplinary activities across different disciplines in the university. The potential of transdisciplinarity includes collaborative research, teaching and learning and dialogue across the university. Challenges of transdisciplinarity proved to be first understanding the concept itself, foundations of mono-disciplinarity which promote departmental isolations, disciplinary comfort zones, heterogeneity of the university and academics' busy schedules. In spite of the challenges of transdisciplinarity, participants indicated a willingness to engage in transdisciplinary activities.

Keywords: transdisciplinarity; interdisciplinarity; multi-disciplinary; collaborative research; disciplines; universities.

\section{Introduction}

As mentioned by Garutsa and Mahlangu (2014), the question of what transdisciplinarity entails is of pertinence in an era where there are dilemmas in an attempt to define the concept and understand its significance. As such, concepts such as transdisciplinarity, multi-disciplinarity and interdisciplinary are often misunderstood and mistakenly used interchangeably when they are in fact different (Bunders, Bunders \& Zweekhorst 2015; Ramadier 2004). According to Padurean and Chevereasan (2010):

... while multidisciplinarity studies a topic not in one but several disciplines at the same time, whereas interdisciplinarity is concerned with the links and the transfer of knowledge, methods, concepts and models from one discipline to another, transdisciplinarity, is concerned with what is between the disciplines, across the disciplines and beyond the disciplines, within the dynamics of the simultaneous action of several layers of reality. (p. 128)

Although interdisciplinarity harmonises knowledge from diverse disciplines into one comprehensible whole (Choi \& Pak 2006), multi-disciplinarity uses knowledge from diverse disciplines but remains confined within one boundary. According to Jones (2009), the advantage of interdisciplinarity is the enhancement of student understanding and communication skills, while the disadvantage is integration confusion and the time-consuming curriculum preparation. When it comes to multi-disciplinarity, Naturejobs (2017) outlines its advantages as being able to combine the expertise of one's field with other fields and create a varied team, which may lead to creative and impactful research resulting in innovative solutions. Naturejobs (2017) further explained that multi-disciplinarity allows people to work on projects that involve more than 
one discipline. Cuevas et al. (2012) indicated it to be a challenge to meet the constraints of different stakeholders with different agendas and conflicting data collection requirements which may hinder the project team's ability to meet all their members' different research objectives. Transdisciplinary moves beyond interdisciplinary by engaging with production, use of knowledge and involving both academic and non-academic stakeholders in the process (Chuenpagdee 2018). Thus, the transdisciplinary approach surpasses interdisciplinary and multi-disciplinary approaches as it better addresses complex problems (Back, Greenhalgh-Spencer \& Frias 2015).

\section{The origins of transdisciplinarity}

The beginning of transdisciplinarity can be traced to the 1970 conference held at the University of Nice in France, sponsored by the Organisation for Economic Cooperation and Development and the French Ministry of Education (Bernstein 2015; McGregor 2015; Nicolescu 2010). It was first discussed following an intense debate on governmentsupported science and the role of higher education institutions. Jean Piaget, a Swiss psychologist has been credited for coining the term transdisciplinarity (LópezHuertas 2013; Nicolescu 2010; Padurean \& Chevereasan 2010). In his 1972 essay 'The epistemology of interdisciplinary relationships', Piaget concluded that there is a connection between disciplines and there should be a systematic way in which different disciplines work together without boundaries (Bernstein 2015). Although the early transdisciplinary dialogue was focused on the theories of knowledge production and the function of universities in the 1970s, there was a paradigm shift in the 1990s where transdisciplinarity re-surfaced as a solution to complex global concerns stretching from climate change and sustainability to social problems such as poverty and HIV and/or AIDS. Today transdisciplinarity focuses on providing solutions to the world's 'wicked problems' (Bernstein 2015). Its popularity has been influenced by the escalation of complex social problems that proved difficult to be solved by mono-disciplinary, interdisciplinary or multi-disciplinary approaches (Lawrence 2010; McGregor 2004, 2006).

Transdisciplinary philosophers such as Nicolescu (2002) initially built on Aristotle's paradigm of rules of good thought, which articulates the duality of life where something is either black or white (Mitchell \& Ross 2018). In this black or white duality, the grey area is unnoticed in making sense of the world. Transdisciplinary prospects thus critique the dualistic perspective of viewing the world as it views disciplines as separate entities meant to operate in silos, and ignores the overlapping grey areas. Thus, transdisciplinarity goes beyond dualism, it promotes interconnectivity of the world, hence including the grey space between the black or white dualism. Transdisciplinarity fights separatism by finding links between previously singular disciplines (Mitchell \& Ross 2018). Although the concept of transdisciplinarity has seemingly changed over time, this study agrees with Polk (2014) and Cronin (2008) that in order to confront complex issues and societal problems such as climate change or health problems, there is a need to engage in transdisciplinarity to bridge the knowledge production gap and produce robust solutions through collaborative research and knowledge integration.

\section{The role of universities}

According to Bernstein (2015), amongst other reasons, transdisciplinarity was initially meant to give direction to the future of universities in the 1970s. Thus, as the biggest suppliers and channels of knowledge (Brennenraedts, Bekkers \& Verspagen 2006), universities are expected to play an important role of providing a platform to facilitate transdisciplinarity, which engages production, use of knowledge and involvement of non-academic stakeholders across different disciplines and communities to solve problems. Nicolescu (2012) argues that the need for transdisciplinarity is necessary and realistic in order for universities to survive as it forces them to interact with different stakeholders. Despite numerous calls for transdisciplinarity and transdisciplinary research (Davids 2018; Le Grange 2017), not much work has been conducted on the role, potential and challenges of transdisciplinarity in the universities of South Africa. Thus, this study sought to define transdisciplinarity from the participant's perspective and locate the role of the Centre for Transdisciplinary Studies (CTS), the transformative potential of transdisciplinarity and its challenges through the lens of academic staff members at the University of Fort Hare, South Africa.

\section{The nature of transdisciplinarity at selected universities in South Africa}

Despite transdisciplinarity being a very critical approach needed to address endemic challenges, few universities have adopted it. Some educational institutions that have adopted the transdisciplinary approach in their teaching and research are the University of Pretoria, Rhodes University, Witwatersrand University, Stellenbosch University and the University of Fort Hare. The University of Pretoria (2018) opened a new Future Africa campus where a community of academic and non-academic stakeholders engage and address challenges faced by Africa stretching from good governance, sustainable development, human rights and citizen participation.

On the other hand, Stellenbosch University has advanced transdisciplinarity through offering a doctoral programme in Transdisciplinary Studies. Their doctoral programme's crosscutting themes include food systems, water systems, energy systems and urban systems. Stellenbosch University's (2018) Centre for Complex Systems in Transition, in collaboration with stakeholders such as the Council for Scientific and Industrial Research (CSIR), the Human Sciences Research Council (HSRC) and the Sustainable Institute (SI), facilitate this doctoral programme. 
The Global Change Institute (GCI) at the University of the Witwatersrand (2017) also uses transdisciplinarity as a corner stone to drive and engage with society. According to its website, 'the GCI addresses problems related to global change, climate change and sustainability in a multidisciplinary and transdisciplinary manner' (University of Witwatersrand 2017).

Rhodes University's transdisciplinary research aims at mobilising transdisciplinary scholarship through research efforts done collaboratively by postgraduate students (Rhodes University Transdisciplinary Research Group 2016). Departments that work closely and in collaboration with the Transdisciplinary Research Group include the Institute of Water Research (IWR), Environmental Learning Research Centre (ELRC) and the Development of Environmental Science. Compared with other universities, the transdisciplinary research programme at Rhodes is largely student-centred where students seek help from one another even without the involvement of staff members (Rhodes University Transdisciplinary Research Group 2016).

In addition to universities advancing the transdisciplinary scholarship, the recognition for transdisciplinary work within the research field has also been created through other platforms. The Journal for Transdisciplinary Research in Southern Africa allows publication of research papers that have been carried out by scholars from other disciplines (African Online Scientific Information Systems 2018).

The CTS at the University of Fort Hare houses a compulsory first year course called 'Life, Knowledge, and Action', which was launched in 2009. The course is transdisciplinary in nature in that it bridges traditional boundaries between disciplines and practice where students across faculties collectively discuss world problems, find solutions to these predicaments and put together their knowledge from their diverse fields of study (Garutsa \& Mahlangu 2014).

\section{Research methodology}

Semi-structured interviews were used as these act as an open platform, giving freedom to respondents to express their views and researchers an opportunity to probe whenever a need arises, hence creating a conversational two-way communication. Semi-structured interviews are a reliable and comparable source of qualitative data as they are usually accompanied with follow-up questions on any matter under discussion. The semi-structured interviews comprised a list of open-ended questions scribed in the interview guide (see Appendix 1) and the interviews were recorded digitally. According to De Vos (2002) an interview guide is a guideline for the interviewer and contains questions and themes that are important to the research. The study employed the stratified random sampling technique in which the university's academic population was first divided into faculties (stratas) and the respondents were randomly selected from these stratas. Upon using this sampling technique the participants were randomly selected from the university's academic staff
TABLE 1: Participants sampled from faculties and centres.

\begin{tabular}{llc}
\hline Faculty or centre & Department & Number of participants \\
\hline Management and & Business management & 2 \\
& Industrial psychology & 1 \\
& Economics & 1 \\
Teaching and & Teaching and learning centre & 2 \\
learning centre & & \\
Law & Law & 3 \\
Health sciences & Human movement sciences & 3 \\
Social sciences & Communications & 1 \\
and humanities & Social work & 1 \\
& Political sciences & 1 \\
Science and & Agricultural economics & 1 \\
agriculture & Chemistry & 1 \\
& Microbiology and biochemistry & 1 \\
Education & Education & 1 \\
\hline Total participants & - & 19 \\
\hline
\end{tabular}

members representing the faculties of health, law, social sciences and humanities, management and commerce, science and agriculture, education and the Teaching and Learning Centre (TLC). Once participants agreed to participate in the study, the interview took place at a time and date convenient to the participant. In total 19 academics participated in the study (see Table 1). The digitally recorded interviews were transcribed and the relevant themes were sought until data were saturated.

Ethical matters were discussed with respondents in terms of informed consent, confidentiality, anonymity and management of information. Participants were assured that pseudonyms would be used when citing their responses. The data were analysed using thematic data analysis. Data were narrowed down into parts that represented segments of raw data. The global categories retrieved from the data were then narrowed down into smaller sub-units. When units for analysis became fewer, emerging categories were continuously refined and compared against each other until saturation was reached.

\section{Ethical considerations}

The ethical clearance to conduct this study was obtained from the University of Fort Hare, Centre for Transdisciplinary Studies (CTS) (REC-270710-028-RA Level 1). An ethical clearance certificate was issued by the University Research Ethics Committee which provided assurance that all ethical standards were adhered to.

\section{Results}

\section{Understanding of transdisciplinarity}

In order to solicit an understanding of the role, potential and challenges of transdisciplinarity from participants, the researchers first asked the participants their understanding of transdisciplinarity. Below are the thematic views about transdisciplinarity according to the academics interviewed:

\section{Merging of disciplines}

A number of participants from different university faculties indicated their understanding of transdisciplinarity as the 
merging of different disciplines. Participant B said that transdisciplinarity involves:

'... merging together various disciplines.' (Participant B, male, lecturer)

Participant D said:

'... it's incorporating knowledge from other disciplines outside your own', while Participant E replied, 'it's different disciplines meeting together.' (Participant D, male, lecturer)

\section{Collaboration of disciplines}

A significant number of participants defined transdisciplinarity as the collaboration of different disciplines. Participant B, for instance, said:

'... work on a common goal, so I think that is the idea, no matter how diverse or different disciplines.' (Participant B, male, lecturer).

While there has been a common consensus on the concept of transdisciplinarity amongst many participants, most of them often used it interchangeably with multi-disciplinarity/ interdisciplinarity. There is evidence that some respondents failed to define the concept. Participant $\mathrm{O}$ said the following:

'Transdisciplinarity is where people from different fields get together to get a new idea. I think I have been always confusing the two, so what I always understood to be as multi-disciplinary is transdisciplinary. So they just saying multi-disciplinary is just kind of where you have forum where people present their own disciplines.' (Participant $\mathrm{O}$, female, lecturer)

Participant R indicated:

'So in other words, by the interdisciplinary research we mean there is actually supposed to be a connectivity between various disciplines within the university.' (Participant $\mathrm{R}$, female, lecturer)

\section{Role of transdisciplinarity in the university}

The respondents concurred that for transdisciplinarity to be realised effectively in an institution that was accustomed to mono-disciplinarity, there was a serious need for a transdisciplinary unit to play the facilitation role. The university's CTS was deemed to be an appropriate unit to play the role. Below are thematic views about the role of CTS.

\section{Raise transdisciplinary awareness in the university}

Respondents consensually indicated that the CTS should raise awareness in the university community on transdisciplinary research and collaborations.

\section{Participant B said:}

'It is that idea of conscientising [sic] other departments with that thing of saying we may focus on real world challenges.' (Participant B, male, lecturer)

\section{Facilitating and coordinating transdisciplinary activities in the university}

Other participants articulated the role of transdisciplinarity as coordination of all transdisciplinary activities in the university.
Participant B said:

'... so it becomes the transdisciplinary department's baby to make sure that it invites people to partake in such kinds of projects because really we cannot say people are not willing as I cannot say I have been offered.' (Participant B, male, lecturer)

Participant N said:

'... the role of the centre is to encourage departments to coordinate and work together and ensure that topics of research that are going across departments are collectively tackled, thus removing the limitations of uni-disciplinarirty and welcoming the notion of transdisciplinarity.' (Participant N, female, lecturer)

Participant I said:

'... I mean that the CTS should play an encouraging role and foregrounding a necessity and desirability of transdisciplinary approaches in the university.' (Participant I, male, lecturer)

While Participant $S$ also articulates the CTS' role of facilitating different departmental collaborations as follows:

'... the role of the centre is to facilitate interaction and build relationships between departments through organising and convening luncheons, seminars and workshops where all departments and faculty representatives as well as other stakeholders both inside and outside the university are invited to discuss this concept.' (Participant S, female, lecturer)

\section{Participant K said:}

'I should think its bringing together all the different disciplines that are within the university, extra mural and academics and also the support and administrative.' (Participant K, female, lecturer)

\section{Potential of transdisciplinarity \\ Collaborative research}

The research participants highlighted several potentials of transdisciplinarity such as collaborative research and other academic activities across different faculties.

Participant N said:

'Different departments can also collaborate through writing academic papers, articles and conference papers on topics that are cutting across for instance social work and other disciplines or even topics that spun across these different departments.' (Participant N, female, lecturer)

After articulating the potential of transdisciplinarity in the university, most respondents showed a willingness to engage in transdisciplinary teaching and research.

Participant J said:

'I will be very willing to become part of a process where we can discuss possible transdisciplinary research and even teaching.' (Participant J, female, lecturer)

\section{Participant L said:}

'I think I would definitely like to be part of it, especially in research.' (Participant L, male, lecturer) 
While Participant M said:

'Yes I'm so much interested in becoming a stakeholder and I'm interested in organising workshops and seminars where academics, researchers and people with various expertise come together to discuss topical issues.' (Participant M, male, lecturer)

Participant S said:

'Yes, of course, I am very interested, I would like to be organising workshops and seminars where the concept of transdisciplinarity is promoted.' (Participant $\mathrm{S}$, female, lecturer)

\section{Collaborative teaching}

Participant S said:

'There are many areas where these two can collaborate, including teaching, assessments, curriculum improvement and research and so on.' (Participant S, female, lecturer)

\section{Collaborative seminars}

Participant M stated:

'... we can jointly hold periodic workshops and seminars highlighting the importance of transdisciplinarity.' (Participant $\mathrm{M}$, male, lecturer)

\section{Challenges of transdisciplinarity Understanding transdisciplinarity}

In this study, some respondents cited the lack of understanding of the importance of transdisciplinarity as a challenge. Participant A indicated:

'I would also say people understanding its importance, I think that could also be a challange.' (Participant A, female, lecturer)

\section{Participant N said:}

'Another challenge that Isee is that there is serious misunderstanding and misconceptions about what transdisciplinary means at this university both among the staff and also the students. If you check my responses, you can also see that I also do not have a clear picture of what transdisciplinarity really means. I am using transdisciplinary and the first year course Life, Knowledge, Action (LKA) interchangeably.' (Participant N, female, lecturer)

Participant $S$ also cites lack of understanding and information on transdisciplinarity by saying the following:

\begin{abstract}
'... there is literally no circulation of knowledge regarding transdisciplinary at this university. I am sure academics do not know exactly what it is and what it is trying to achieve and its importance and so forth. Therefore, some academics are obliged to naturally resist it and stick to departmental specialisation.' (Participant S, female, lecturer)
\end{abstract}

\section{Foundations of mono-disciplinarity and specialisation}

A sizeable number of participants highlighted the 'coming together of experts' who specialise in homogenous departments as a huge challenge for collaboration. This is noted as departmental specialisation.
Participant S said:

'... the challenge is the rigidities that come with curriculums. Most departments have rigid curriculums that promote uni-disciplinarity instead of transdisciplinarity. Therefore, without flexible curriculums, implementing trandisciplinarity will be a huge challenge in universities.' (Participant S, female, lecturer)

Transdisciplinarity demands flexibility and harmonisation of efforts by various professionals. As highlighted by Pohl and Hardon (2008), transdisciplinarity enables experts in various fields to come together, analyse and comprehend the complexity of problems, view problems from diverse scientific perceptions and link them to integrated knowledge systems. Participant I states:

'I think most of us as teachers were not taught that model (transdisciplinarity), we were taught within singular disciplines.' (Participant I, male, lecturer)

Participant L also says:

'I also think that previous learning or teaching was very individual and in silos, so even teachers or academics struggle to see [a] connection between the different disciplines.' (Participant $\mathrm{L}$, male, lecturer)

McGregor (2015) concurs on this challenge by stating that indeed the diversity of perspectives is a huge challenge for transdisciplinary research because stakeholders from different fields understand reality differently and have different methodological ways of approaching research.

\section{Disciplinary comfort zones and resistance to change}

Five respondents cited disciplinary comfort zones as a challenge to transdisciplinarity. Participant D said:

'People are not comfortable moving from their own comfort zones.' (Participant D, male, lecturer)

Participant J replied:

'... one of the challenges for me that I have already encountered was that people don't have the willingness. I think it is attitude. People are not willing to move beyond their own comfort zones. Because it challenges you when you are going to work across disciplines. To be willing to move and to be willing to adapt and some people do not have that attitude.' (Participant J, female, lecturer)

Participant K said:

'The challenges of transdisciplinarity in any university would be in most cases, the resistance of the people who are already in their comfort zones. For instance if somebody is in his comfort zone in the area of psychology, they might not understand the relationship between psychology, health and wellness.' (Participant K, female, lecturer)

\section{Heterogeneity of the university}

Another challenge of transdisciplinarity mentioned by respondents is the heterogeneity of the university in which people do not know each other. 
Participant J said:

'The other one is people do not know each other, sometimes they do not even know what other people do, that they could collaborate on and if you do not make an effort to sit down and collaborate with colleagues, I think it will be difficult for you to engage in such a research.' (Participant J, female, lecturer)

Two participants cited transdisciplinary publishing as a potential challenge. Participant D said:

'When it comes to publishing, you might find challenges on where to publish it (as journals are usually on singular disciplines).' (Participant $\mathrm{D}$, male, lecturer)

While this might be a concern for researchers, there have been strides made to accommodate transdisciplinary research internationally, as well as in South Africa through journals such as The Journal for Transdisciplinary Research in Southern Africa (African Online Scientific Information Systems 2018), the Asian Journal of Transdisciplinary Research, Epiphany: Journal of Transdisciplinary Studies, International Journal of Transdisciplinary Research, to mention just a few. According to Kueffer et al. (2006), there are more than 500 journals publishing transdisciplinary research.

\section{Busy schedules}

Some participants state that one of the challenges of transdisciplinarity is busy schedules, as Participant B said:

'... not everyone has got that time, people are busy.' (Participant $\mathrm{B}$, male, lecturer)

\section{Discussion}

\section{Defining transdisciplinarity}

There was no consensus amongst participants on how to define transdisciplinarity. A number of participants defined transdisciplinarity as the merging of disciplines. Merging occurs when two or more units that are separate combine to create a new joint unity. Therefore, this denotes quite a limited understanding of transdisciplinarity because the approach transcends beyond the mere merging of disciplines, for instance, the approach entails research efforts on problems that cut across disciplines which demands integration of methodologies from diverse disciplines. More so, the approach can refer to methodologies that are developed in one discipline and are now used in several other disciplines. A significant number of participants defined transdisciplinarity as the collaboration of disciplines. Collaboration is logical when different entities work together on a common goal but remain stand-alone entities. Although transdisciplinarity has been largely defined as the collaboration of diverse disciplines, it is noteworthy that participants used the term interchangeably with multi-disciplinarity and interdisciplinarity. Thus, the confusion surrounding the term transdisciplinary itself is a stumbling block to the full and correct implementation of this approach at the University of Fort Hare. It is key that academic and non-academic staff, to be involved in transdisciplinarity, be acquainted with both its theoretical and practical aspects at least within the context of this institution.

\section{Role of transdisciplinarity}

Based on the study results, participants indicated that the CTS should play a facilitative role towards promoting, collaborating and creating awareness around transdisciplinarity within the university. As discussed by Gehlert et al. (2010), there is a need for a centralised unit to take on the facilitative role of transdisciplinarity to bring together scholars from different disciplines to form research teams. Gehlert et al. (2010) continue to state that while universities may have the structure for such a unit, they also need to adopt reward structures for transdisciplinary work. This has been done at other universities such as the University of Pretoria (2018; Future Africa campus); Stellenbosch University (2018; Centre for Complex Systems in Transition); the University of Witwatersrand (2017; The Global Change Institute) and Rhodes University (2016; Rhodes University Transdisciplinary Research Group). While CTS at the University of Fort Hare offers a module 'Life, Knowledge and Action' that cuts across disciplinary boundaries, a conducive environment for transdisciplinary research seems to be a challenge as universities take pride in their collections of segmented and highly specialised disciplines functioning at their own facilities (Carroll et al. 2017). This often leads students to pass through a 'funnel' approach in order to prosper in one specific area and continue to complete training with limited exposure to a larger context of problems and perspectives (Carroll et al. 2017).

\section{Potential of transdisciplinarity}

As the results show, the potential of transdisciplinarity is centred on collaborative research, collaborative teaching and joint seminars. Pohl and Hardon (2008) posited that Transdisciplinary Studies has the potential and capacity to alleviate life's deep-seated challenging problems in the world as it uses integrated, practice-oriented and normative knowledge systems. This can only be done through collaborative activities as mentioned by participants in this study that allows academic engagement. Pohl and Hardon (2008) state that different stakeholders stand to benefit from transdisciplinarity as each individual can play a significant but unique role in the process. Although participants were not asked whether they are or would be willing to engage in transdisciplinary activities in the university, a significant number of them indicated a willingness which could be a good starting point if we are to advance transdisciplinarity.

\section{Challenges of transdisciplinarity}

\section{Understanding transdisciplinarity}

Two participants were evidently confused regarding the meaning of the term transdisciplinarity. This corresponds with Byrne, Mullally and Sage (2016) who indicate that 
there is no universal definition of transdisciplinarity. As mentioned by Rousseau et al. (2018), the term has become popular with a diversity of nuanced meanings as there are differences in opinions about its nature, scope, value and potential (Rousseau et al. 2018). This seems to create a lack of consensus on the definition of transdisciplinary (Sakao \& Brambila-Macias 2018).

As mentioned by Gibbs (2015), there have been many definitions proposed by scholars since the 1970s and therefore it becomes difficult to settle on one definition thereof. Participants of this study highlighted that it meant merging different disciplines, while others defined transdisciplinarity as the collaboration of disciplines. This appears to be in line with Davids' (2018:2) understanding of transdisciplinarity as it crosses 'disciplinary boundaries'. A practical example of a transdisciplinary project is that of Davids (2018) whose research involved various researchers working at different universities in South Africa. It is often described as a mode of collaborating outside your own disciplinary boundary (Gehlert et al. 2010). As Pohl and Hardon (2008) mentioned, in transdisciplinary research projects, it is mandatory to define common goals, and this was indicated by four participants that for transdisciplinarity to occur a common goal amongst stakeholders is needed.

\section{Disciplinary comfort zones and resistance to change}

Transdisciplinary collaboration is not easy, especially for multiple stakeholders' involvement (Russel 2005). In this study, participants noted the challenge for individuals to come out of their 'comfort zones'. This concurs with a challenge raised by Gehlert et al. (2010) who indicated that individuals are more comfortable with what they know than to operate with a different viewpoint, methods of communication and knowledge that is different to their own. Thus, adopting a transdisciplinary approach would extend individual's boundaries which requires buy-in as often there are a limited number of investigators who are willing to put in their time, effort and preparation required by transdisciplinary collaborations (Gehlert et al. 2010). This requires patience, time and commitment from academics and institutions (Nowotny 2003). Even locating and engaging with individuals to collaborate in transdisciplinary work becomes a challenge (Gehlert et al. 2010).

\section{Foundations of mono-disciplinarity and specialisation}

Participants in this study noted the possible challenge of the coming together of individuals from different specialisation fields which are often rigid in nature. Concurring with this challenge is Carroll et al. (2017) who suggest that universities take pride in their collections of segmented and highly specialised disciplines functioning in their own facilities, hence moving beyond these disciplines is a challenge that calls for the creation of conducive environments for transdisciplinary research. This then often leads to university staff not knowing about what projects other staff are involved in, as mentioned by participants in this study. Conventionally, academic advancement has been a solo journey and the tenure clock is not set to incorporate time that is taken to build and maintain transdisciplinary teams (Gehlert et al. 2010).

\section{Heterogeneity of university and academics' busy schedules}

Other challenges highlighted in this research were academics' busy schedules and the heterogeneity of a university. A university is a large entity with the possibility that many departments are not aware of the existence of others. Some of these disciplines' roles may not overlap anyhow to allow any discussion on transdisciplinarity. To respond to the concern of busy schedules as hindering transdisciplinary research, Kuaffer et al. (2006) indicate that in order to promote a culture of transdisciplinary publishing there needs to be a shift in thought and priorities of researchers, publishers, reviewers and perhaps even readers.

\section{Recommendations}

This research recommended that CTS at the University of Fort Hare should take the lead in facilitating and driving transdisciplinary activities in the university. Although the university is generally heterogeneous, the CTS should find ways to promote transdisciplinarity amongst university stakeholders.

\section{Conclusion}

The concept of transdisciplinarity changes in meaning and evolves over time. As a way of reconceptualising the goals of CTS at the University of Fort Hare, the article sought to explore the roles, potentials and challenges of transdisciplinarity. The challenges of transdisciplinarity as articulated by participants range from the lack of knowledge on the concept of transdisciplinarity to disciplinary specialisation and resistance to change. The role and potential of transdisciplinarity stood out as a collaborative research and the creation of partnerships with various stakeholders. Respondents showed a willingness to engage with the CTS which provides insight to their realisation of the importance of transdisciplinarity at the University of Fort Hare.

\section{Acknowledgements Competing interests}

The authors have declared that no competing interests exist.

\section{Authors' contributions}

C.E.W. conceptualised and developed the final title, argument and layout of the article and also verified and added the literature on transdisciplinarity, data collection and data analysis. N.D. conceptualised the article and developed the final title, argument and also verified and added the literature on transdisciplinarity and data collection. S.N. and C.T.C. conceptualised the article and were responsible for data collection and proofreading. 


\section{Funding information}

This research received no specific grant from any funding agency in the public, commercial or not-for-profit sectors.

\section{Data availability statement}

Data sharing is not applicable to this article as no new data were created or analysed in this study.

\section{Disclaimer}

The authors declare that this work is a summary of their own findings and not the views of the institution.

\section{References}

African Online Scientific Information Systems, 2018, The Journal for Transdisciplinary Research in Southern Africa, viewed 10 March 2018, from https://td-sa.net/index. $\mathrm{php} / \mathrm{td} /$ pages/view/journal-information

Back, S.M., Greenhalgh-Spencer, H. \& Frias, M.F., 2015, 'The application of transdisciplinary theory and practice to STEM education', in Y. Rosen, S. Ferrara \& M. Mosharraf (eds.), Handbook of research on technology tools for real-world skill development, pp. 42-67, IGI Global, Hershey, PA.

Bernstein, J.H., 2015, 'Transdisciplinarity: A review of its origins, development, and current issues', Journal of Research Practice 2(1),1-20.

Brennenraedts, R., Bekkers, R. \& Verspagen, B., 2006, The different channels of universityindustry knowledge transfer: Empirical evidence from biomedical engineering viewed 26 September 2019, from https://citeseerx.ist.psu.edu/viewdoc/download ?doi=10.1.1.543.6736\&rep=rep1\&type=pdf

Bunders, J.F.G., Bunders, A.E. \& Zweekhorst, M.B.M., 2015, 'Challenges for transdisciplinary research', in B. Werlen (ed.), Global sustainability, pp. 17-50, Springer, Cham.

Byrne, E., Mullally, G. \& Sage, C., 2016, Transdisciplinary perspectives on transitions to sustainability, Routledge, New York.

Carroll, L., Ali, M.K., Cuff, P., Huffman, M.D., Kelly, B., Kishore, S.P. et al., 2017 'Envisioning a transdisciplinary university', Journal of Law Medical Ethics 42(2), 17-25. https://doi.org/10.1111/jlme.12183

Choi, C.K. \& Pak, A.W.P., 2006, 'Multidisciplinary, interdisciplinarity and transdisciplinarity in health research, services, education and policy: Definitions, objectives and evidence of effectiveness', Clinical Investment in Medicine 29(6), 351-364.

Chuenpagdee, R., 2018, Transdisciplinarity for small-scale fisheries governance: Analysis and practice, Springer, St. John's.

Cronin, K., 2008, Transdisciplinary research (TDR) and sustainability, overview report prepared for the ministry of research, science and technology (MORST), viewed 03 March 2018, from https://learningforsustainability.net/pubs/ Transdisciplinary_Research_and_Sustainability.pdf

Cuevas, H.M., Bolstad, C.A., Oberbreckling, R., LaVoie, N., Mitchell, D.K., Fielder, J. et al., 2012, 'Benefits and challenges of multidisciplinary project teams: "Lessons learned" for researchers and practitioners', The ITEA Journal (International Test and Evaluation Association) 33(1), 58-65

Davids, M.N., 2018, 'From history project to transdisciplinary research: District six as a case study', The Journal for Transdisciplinary Research in Southern Africa $14(2), 1-8$.

De Vos, A.S., 2002, 'Combined qualitative and quantitative approach', in A.S. De Vos, H. Strydom, C.B. Fouche \& C.S.L. Delport (eds.), Research at grass roots: For the social sciences and human service professions, pp. 24-45, Van Schaik, For the socic
Pretoria.

Garutsa, T.C. \& Mahlangu, P.M., 2014, 'Using transdisciplinarity in the university: Giving a voice to the voiceless in the grounding program at Fort Hare', The Journa for Transdisciplinary Research in Southern Africa 10(3), 310-322. https://doi.org/ 10.4102/td.v10i3.179

Gehlert, S., Murray, A., Sohmer, D., McClintock, M., Conzen, S. \& Olopade, O., 2010, 'The importance of transdisciplinary collaborations for understanding and resolving health disparities', Social Work in Public Health 25(3), 408-422. https:// doi.org/10.1080/19371910903241124
Gibbs, P., 2015, Transdisciplinary professional learning and practice (Middlesex University, UK), Springer, New York.

Jones, C., 2009, 'Interdisciplinary approach - Advantages, disadvantages, and the future benefits of interdisciplinary studies', ESSAl: The College of DuPage Anthology of Academic Writing Across the Curriculum 7(26), 76-81.

Kueffer, C., Hadorn, G.H., Bammer, G., Van Kerkhoff, L. \& Pohl, C., 2006, 'Towards a publication culture in transdisciplinary research', GAIA: Ecological Perspectives for Science and Society 16(1), 22-26. https://doi.org/10.14512/gaia.16.1.8

Lawrence, R.J., 2010, 'Deciphering interdisciplinary and transdisciplinary contributions', Transdisciplinary Journal of Engineering and Science 1, 125-130.

Le Grange, L., 2017, '(Trans)disciplinary research (re)considered', South African Journal of Higher Education 31(6), 167-176. https://doi.org/10.28535/31 6-1656

López-Huertas, M., 2013, 'Reflexions on multidimensional knowledge: Its influence on the foundation of knowledge organization', Knowledge Organization 40(6), 400-407.

McGregor, S.L.T., 2004, The nature of transdisciplinary research and practice, viewed 14 March 2018, from https://www.kon.org/hswp/archive/transdiscipl.pdf

McGregor, S.L.T., 2006, Transformation practice, Kappa Omicron Nu, East Lansing, MI.

McGregor, S.L.T., 2015, 'Transdisciplinary knowledge creation', in P.T. Gibbs (ed.), Transdisciplinary professional learning and practice, pp. 9-24, Springer, New York.

Mitchell, C. \& Ross, K., 2018, Transforming transdisciplinarity: Interweaving the philosophical with the pragmatic to move beyond either/or thinking, viewed 28 September 2019, from https://i2insights.org/2018/11/13/transdisciplinarityand-either-or-thinking/

Naturejobs, 2017, 'Multidisciplinary research: Pros and cons', viewed 01 October 2019, from https://blogs.nature.com/naturejobs/2017/09/11/multidisciplinary-researchpros-and-cons/

Nicolescu, B., 2002, Manifesto of transdisciplinarity, State University of New York Press, Albany, NY.

Nicolescu, B., 2010, 'Methodology of transdisciplinary - Levels of reality, logic of the included middle and complexities', Transdisciplinary Journal of Engineering and Science 1(1), 19-38.

Nicolescu, B., 2012, 'The need for transdisciplinarity in higher education in a globalized world', Transdisciplinary Journal of Engineering \& Science 3, 11-18.Nowotny, H., 2003, 'The potential of transdisciplinarity', in Rethinking interdisciplinarity, interdisciplines project, viewed 26 September 2019, from https://www.worldfishcenter.org/sites/ default/files/The $\% 20$ potential $\% 20$ for $\% 20$ transdisciplinarity.pdf

Padurean, A. \& Chevereasan, C.T., 2010, 'Transdisciplinarity in education', Journal Plus Education/Educatia Plus 6(1), 127-133.

Pohl, C. \& Hardon, G.H., 2008, 'Methodological challenges of transdisciplinary research', Natures Sciences Societies 16(2),111-121. https://doi.org/10.1051/nss: 2008035

Polk, M., 2014, 'Achieving the promise of transdisciplinarity: A critical exploration of the relationship between transdisciplinary research and societal problemsolving', Sustainability Science 9(4), 439-451. https://doi.org/10.1007/s11625014-0247-7

Ramadier, T., 2004, 'Transdisciplinarity and its challenges: The case of urban studies', Science Direct 36(4), 423-439. https://doi.org/10.1016/j.futures.2003.10.009

Rhodes University, 2016, 'Transdisciplinary research exploratory training workshop', Rhodes University transdisciplinary research group, viewed 09 March 2018, from https://www.ru.ac.za/media/rhodesuniversity/content/iwr/documents/Final_ Report_RU-TD_workshop_May_2016.pdf

Rousseau, D., Wilby, J., Billingham, J. \& Blachfellner, S., 2018, General systemology: Transdisciplinarity for discovery, insight and innovation, Springer, Singapore.

Russel, A.W., 2005, 'No academic borders? Transdisciplinarity in university teaching and research', Australian University Review 48(1), 35-41.

Sakao, T. \& Brambila-Macias, S.A., 2018, 'Do we share an understanding of transdisciplinarity in environmental sustainability research?' Journal of Cleaner Production 170, 1399-1403.

Stellenbosch University, 2018, Centre for complex systems in transition, viewed 03 September 2018, from https://www0.sun.ac.za/cst/about/who-we-are/

University of Pretoria, 2018, Future Africa campus, viewed 30 September 2018, from https://www.up.ac.za/future-africa

University of Witwatersrand, 2017, 'What we do: Research, teaching and academic citizenship', Global change institute, viewed 15 March 2018, from https://www. wits.ac.za/gci/what-we-do/ 


\section{Appendix 1 \\ Interview guide}

\begin{tabular}{|l|l|}
\hline Name of interviewer & \\
\hline Pseudonym or number of interviewee & \\
\hline Date of interview & \\
\hline University Faculty & \\
\hline University Department & \\
\hline
\end{tabular}

1. In your understanding, what is transdisciplinarity?

2. What do you think are or can be the challenges of transdisciplinarity in any university?

3a. What knowledge do you have about the Centre for Transdisciplinary Studies at the University of Fort Hare?

3b. What do you think is the role of the transdisciplinary centre vis-à-vis other university units, centres, faculties and departments?

3b(i). In your view, how can the Transdisciplinary Studies centre work/collaborate with your department?

4. Have you, for academic purposes, interacted with the Centre for Transdisciplinary Studies? If so, for what reasons?

5. Beyond all you know about the centre, what do you think is the ideal role that should be played by the Centre for Transdisciplinary Studies considering the current state of the University of Fort Hare and its historic past?

6. Would you consider being a stakeholder at the Centre for Transdisciplinary Studies? If so, what role would you like to play? 